\title{
1
}

\section{National Novel and New Architecture}

Modest methodological proposal for the cultural-historical dialectic. It is very easy to establish oppositions, according to determinate points of view, within the various 'fields' of any epoch, such that on one side lies the 'productive', 'forward-looking', 'lively', 'positive' part of the epoch, and on the other side the abortive, retrograde, and obsolescent.

-Benjamin (Arcades, [N1a, 3], 459)

This book traces the relationship and the intersections between the theory and practice of the novel and architecture in Italy during the Fascist regime (1922-1943), a period which saw an institutional body actively trying to shape the artistic world through a series of political choices and a system of patronage, which had distinct aesthetic reverberations. ${ }^{1}$ Our initial hypothesis is that the aesthetic urgency of renewing the novel runs parallel to that of reconstructing a new architecture with the aim of creating an arte di Stato, or 'State art'. This monograph considers these issues over the entire duration of the regime, with particular focus on the first half of the 1930s, the moment in which these aesthetic projects, the structural reforms planned as well as the consensus enjoyed by the regime were at their height. 
Throughout the arch of its lifespan but more so from the late 1920s to the mid-1930s, the regime presented itself as a modern, totalitarian political apparatus seeking to modernize the country's infrastructures, and the arts had to offer their contribution to these endeavours. Thus, our general argument is that an effort of construction, or reconstruction, was the main driving force behind the advocated 'revolution' of the novel form (realism) and of architecture (rationalism) called for by commentators and practitioners, both sustaining the 'anthropological revolution' brought about by Fascism, and creating spaces for the 'New Man'. As far as the arts were concerned, on the one hand, there was general consensus amongst novelists, publishers and intellectuals that the national novel needed to be rebuilt as a solid narrative form, reversing the nineteenthand early twentieth-century trends towards Decadentism, art for art's sake, solipsism and the prosa d'arte, to address the demands of the growing Italian reading public. On the other, a generation of critics and relatively young architects explicitly argued that architecture had to be refounded and deployed in the service of building collective spaces for the New Fascist Man within a modernized social sphere. These aesthetic projects, then, both aimed at the cultural and social transformation of the new nation through a reconstruction and rationalization of artistic forms, and were marked by a strong belief in the moral and social role of art, which should sublimate individual experience into an anti-bourgeois collective narrative and spectacle. Both projects, catalysts as they were of the Fascist way to modernity, drew inspiration from foreign sources, and in this way, they were both instrumental in the process of the internationalization of Italian culture, while reclaiming the collective and nationspecific sense of artistic expression.

The fields of the novel and architecture became the subject of extensive discussions in public fora and in literary and cultural journals of different political orientations, as one can see throughout our analysis. These debates were at once theoretical, technical, aesthetic and political in nature, and on occasions intersected with each other to a remarkable degree. The journals hosting these arguments acted as spaces to theorize first and construct after a modern cultural infrastructure on which to base a process of modernization of the public sphere (e.g. publishing industry and State-commissioned public buildings), with the debate on the realist 
novel and rationalist architecture at its centre. Despite the different perspectives from which they were conducted, these debates on the novel and architecture tended to focus particularly on the need to rationalize current aesthetic practices_-in terms of both formal structures, stylistic renderings and thematic repertoires - in order to respond to a widespread need to modernize the cultural and social spheres and make them more suitable to the needs expressed by the citizens (the new New Man), who had been shaped by the Fascist regime. To this end, from 1926 the regime started a campaign to support the arts both financially and politically, which is discussed in Chap. $2 .^{2}$ The regime not only produced the libro di Stato but also entered into profitable dialogue with the publishing industry in order to gain mutual benefit; this became even more prevalent in the 1930s. ${ }^{3}$ Not dissimilarly, prominent cultural agents and architects wanted architecture to be elevated to the status of official State art. If this was a difficult task as far as private housing was concerned, from the early 1930s onwards, the collective dimension of the art of building was supported by the State and a specific architectural language (the stile littorio) was progressively developed. ${ }^{4}$

By returning to these topics in a concerted and consolidated fashion and not as individual projects, the main point this book seeks to make regards the importance of looking at a cultural system, in this case the system of the arts during the Italian dictatorship, as a series of intersections of cultural, political and aesthetic discourses in order to understand both how the arts could contribute to the political and cultural discourse of the regime and how a cultural system was designed and needed to work as an integrated whole rather than as self-defined fields of cultural production. Once this is established, it is crucial to determine how and why this is the case, and the degrees of such interconnectedness. To this end, we have chosen to analyse these connections in relation to the debates on State art. The creation and shaping of a Fascist arte di Stato became a major concern for the regime after the Matteotti affair in 1924, following the 1927 Discorso dell'Ascensione, in which Mussolini called for the andata al popolo, and particularly in the years of consolidation of consensus after the Patti lateranensi in 1929 and the proclamation of the Empire in 1936. In this context, debates on State art, on the form and content of the novel, and on new architecture often assumed a performative 
tone: in other words, they assumed a meaning not only when realized in practice but also when articulated either in writing or verbally. The system of the arts understood as such became a space where political and aesthetic aims could meet not only to produce forms of propaganda but also to create a discursive apparatus, which could embody the regime's ideology through experimental and anti-representational iconologies, designs and poetics. The arts and their intersecting theorizations did not necessarily aim at achieving a practical result, but rather at supporting the building of an aesthetic apparatus engendered by the regime with the political ambition of transforming the lives of Italian citizens; this was especially the case after 1932 and the Mostra del Decennale. ${ }^{5}$

Having identified similarities between the two projects under examination, it is necessary to reflect on their respective differences. The novel was never directly sponsored by the regime. Publishers (including Mondadori) did not receive systematic financial support: rather, the agreement between the parties was on a mutual understanding of each other's needs and priorities in order to avoid the publication of subversive, or even too controversial, material, as was made explicit in the case of translations. There were exceptions of course. In contrast, architects took part in public competitions and received direct financial support from the regime when engaged in the construction of public buildings: train stations, post offices, corporativist cities, the Sapienza University, public buildings for State functions and the E42 as a final attempt at building a new Rome are some of the most obvious examples. Public competitions attracted great interest and were the subjects of extensive debates. Architectural achievements were reviewed and discussed in literary journals and weekly cultural magazines alike. The novel performed its role as traditionally understood within the structures of an expanding publishing industry, while architecture gained unprecedented popularity because of its visibility and because of the public role it performed. The other difference worth mentioning here concerns the respective ways of reception and enjoyment of the two art forms. Architecture was a visible product that was immediately accessible and which everyone could see and comment upon: it was the product of the conflation of space and concept (see also Tschumi 1996, 39-44). The novel instead remained a much more difficult product to enjoy. It needed financial commitment 
on the part of the reader and it was often not simply a pleasant distraction, but required sustained intellectual attention. Otherwise put, if the Italian 'Fascist' novel was in many ways a failed project because it could not reach a wide enough audience and was eclipsed by translations, the regime's architecture was more successful. Following from what we have just stated, a fairly obvious statement would be to say that the book takes an interdisciplinary approach: the novel and architecture not only belong to rather distant disciplinary fields, but they also reach their audiences through different channels, languages and functions, employing disparate aesthetic practices.

Because of the differences between the two projects we have outlined above, we have decided to focus on how they were theorized in public fora, rather than on the ways in which they were sponsored by the State or enjoyed by the audiences they targeted and addressed. However, in order to paint a coherent picture, we have sampled our sources widely: we have looked at journals of diverse orientations, we have chosen a pool of famous and less well-known examples of novels and of buildings as representative cases embodying the principles we have identified, and we have consulted several archives. The book combines more obvious examples with less obvious ones, since we believe that patterns of cultural production function only when tested across a series of diverse cases spanning high and popular culture, avant-garde and mainstream artefacts. However, if we scrutinize them as interconnected efforts, if we theorize the ways in which they existed within the system of the arts, and, significantly, if we do so under the overarching rubric of State art, we can see similarities emerging across the four main principles that guide these endeavours and share in their aesthetic and political programmes. From scrutiny of the many aesthetic-political debates and theoretical statements, we have identified four cardinal principles, around which we have built our analysis of the 'atlases' of the novel and of architecture, the reading of periodical press and the dissection of the artefacts. These principles are the rationalization of aesthetics, the necessity for morality in the arts, the call for a social and collective mission for the arts, and the need for a new brand of realism. We understood the rationalization of aesthetics as a practice whereby the shaping of an artwork was based on a process of simplification of the subject matter in order to produce a unitary 
construction, while we interpreted the call for morality as an underlying ethical meaning of a given work of art. Principles three and four, concerning the social meaning of art, and the adoption of new forms of realism, are closely connected. Both envisage the work of art as the result of an exchange between subjectivity and objectivity, which has to take place with reference to a social context. They both call for an engagement with objectivity, which instead can give weight to a historicist approach. All principles question the idea of the autonomy of the arts traditionally conceived as detachment from the real, and propose to view autonomy and heteronomy as mutually connected. ${ }^{6}$ The work of art is an autonomous product of the imagination, carefully constructed, which is also closely connected and heteronomous to the contexts of its production.

From a methodological perspective, a few points need to be explained by way of introduction: the definition and understanding of the arts, or the system of the arts under an anti-liberal regime; the distinction between the arts per se and the arts as a system (Cioli 2011, xi); and the overall design of the book. Firstly, we do not view an artistic field in isolation, and we are not interested in any of their individual developments during a particular historical period. We are interested in how distinctive fields interact with each other when occupying different positions within their fields of cultural production. Secondly, our field of cultural production, in this particular case, is shaped by the presence of a dictatorship, which at least from the mid-1920s engaged in the definition and construction of the concept of State art, as discussed in Chap. 2. The presence of an overarching debate on State art called for by a totalitarian State fundamentally changes the modes of production and exchange within any cultural landscape, since it acts as a governing mechanism that cannot be disregarded. By looking at these phenomena as intersecting fields within the overarching project of the State art, we can ask questions which exceed traditional disciplinary boundaries while following a clear conceptual trajectory defined by the key principles outlined above. Thus, in order to assess the relevance of the interconnections between the novel and architecture for the profile of Fascist culture and the culture produced by and within the regime, the main questions we ask are: how and why did the new novel and architecture assume such a privileged position within the Fascist system of the arts? What is the relationship between the 
aesthetic principles governing the theorization of the new novel and those guiding the development of architecture? How did the novel and architecture contribute to shaping the idea of Fascist modernity? To what extent were the arts instrumental to the process of social modernization initiated by the dictatorship? Finally, to what extent did the arts, specifically novel and architecture, contribute to forming the identity of the Italian way to totalitarianism?

Having said that, this book is neither about architecture nor about the novel. Its aim is rather to develop a methodological perspective which is, in turn, neither comparative nor historicist. We are not comparing two distinct phenomena in order to assess what they might have in common, nor are we looking to determine their modes or points of comparison. We are, perhaps, closer to adopting a historicist approach, both when we place the artefacts we analyse in close dialogue with the historical landscape and when we focus on their modes of representation rather than on their 'real' existence. Or else the book aims 'to tread the shadowy paths' that connect artistic and cultural practices, which were juxtaposed under a political banner (Greenblatt 2004, 12). If anything, however, by analysing two distinct cultural fields, the book proposes a way of thinking about culture as a polymorphous field of action, which can be more productively analysed by creating junctures across phenomena that occur simultaneously but belong to diverse artistic fields. This can be achieved by choosing an overarching narrative, which gives coherence to the overall argument and which, in our case, is the narrative concerning the construction of State art under the regime. ${ }^{7}$ One can therefore read this book as a contribution to the cultural history of the Fascist period in Italy from the point of view of the debates on architecture and the novel. We are less concerned with the history of the novel or the history of architecture taken as independent experiences than we are with an interdiscursive analysis of their relations, which can tell us about the aesthetic and political system of the day. In this respect, the book is not about individuals but about projects per se, which assume a relevance if placed within a given historical, political and aesthetic context. We hope to have made a contribution to advancing further the understanding of how the arts interacted with each other under the umbrella of the arte di Stato and how such participation has shaped the idea of Italian totalitarianism 
during the age of the European totalitarian regimes along the pathways identified by academic colleagues in Italy and across the Atlantic from the early 1990 s to the present day.

In our analysis, we have relied heavily on architectural historians and critics of Italy, as well as on literary critics, and historians of Fascism, as we indicate throughout. To date, both architecture and the novel in the Italian Fascist period have received significant critical attention as distinct spheres of research, but have not been extensively analysed in close dialogue; rather they have been studied as isolated endeavours, which seemed to have very little aesthetic and political overlap. In particular, there have until now been no studies that examine them over the long term. As is discussed in every chapter, the theoretical foundation of the project draws on Emilio Gentile's work on modernity and on the anthropological revolution pursued by the regime $(1982,1990,2003)$. The anthropological revolution of (imperfect) totalitarianism had to shape an individual capable of being a social and collective subject; and in order to achieve such a shift in perspective, it had to redefine the very parameters of the concept of realism. This was intended to support the process of the modernization of the public sphere. Arguably, the regime wished to elaborate a system of the arts capable of formulating just such a new expression of a modern and modernized subjectivity: from literature to the visual arts, theatre, architecture and, obviously, to the most powerful weapon, cinematography, what had to be achieved was a system of interdisciplinary arts, which proved to be at the same time official State art but also Art in the Fascist era. ${ }^{8}$ Similarly, the past 20 years have seen a reassessment of the relationship between Fascism and culture in both Italian and Anglo-American scholarship, and especially so from the 1990s onwards. Walter Adamson (1993, 2001), Mark Antliff (2002), Ruth Ben-Ghiat (2001), Emily Braun (2000), Roger Griffin (1998, 2007), Mario Isnenghi (1979), Aristotle Kallis (2014), Jeffrey Schnapp (2003, 2004, 2012), Marla Stone (1998) and Pier Giorgio Zunino (1985) have amply demonstrated the key role played by cultural apparatus in shaping the Italian way to totalitarianism and introduced a new critical vocabulary to discuss culture and fascism: cultural modernities, palingenetic rebirth, the third way, cultural representations as complementary to historical fact, Fascism as a 'discourse', the Fascist regime as the patron State, and the patterns of aesthetic 
pluralism. They have all contributed to furthering our understanding of the complex ideological positions occupied by intellectuals, of the importance attributed to the process of modernization of the country through forms of cultural production which were not exclusively propaganda, of the complex nature of the regime's formulation of the idea of modernity, and of the connections between cultural formations of the pre- and postFascist regime. Fernando Tempesti (1976), Sileno Salvagnini (1988, 2000, 2015), Laura Malvano (1988a) and Monica Cioli (2011) have analysed the steps taken by the regime in the artistic sphere and have produced detailed accounts of the various cultural fronts in this war at any given time. Salvagnini and Cioli in particular have addressed with an impressive wealth of archival material the problem of the system of the arts as a concerted whole, including the issue of state patronage, within a broader interpretative framework which was at the same time historical, cultural and sociological. If Cioli has given prominence to the Futurist participation in the design of the arte di Stato, Salvagnini instead has painted a detailed picture that moves from the grand designs of the exhibitions to State-run local initiatives and the role of private galleries.

Architectural historians have been no less active, and we wish to mention the seminal work by David Rifkind (2012) in the journal Quadrante as an example of cultural analysis of a key phenomenon of the Ventennio, namely rationalist architecture and its politicization. Furthermore, Aristotele Kallis has discussed the matter from the point of view of a historian of culture and thus he has emphasized the importance of the cultural fabric in the reconstruction of an historical landscape of analysis. Of profound significance to our argument too have been the histories of architecture during the regime written by such scholars as Doordan (1988), Ciucci (2002 [1989]), Etlin (1991), Nicoloso (2008), De Seta (1998) and Ghirardo (2013), because of the detailed ways in which they have reconstructed the history of architecture while focusing on its political and technical aspects, problematizing without judgment its complex relationship with the regime. Finally, the work of some art historians, art critics and curators has pioneered the understanding of the arts during the regime as a complex, intersecting system to be studied as such rather than as individual, yet very detailed, discrete occurrences (Danesi and Patetta 1988; Anni Trenta 1982; Pontiggia 1990; Fagone 2001; Celant 
2018). ${ }^{9}$ These scholarly works have provided methodological examples from the visual arts, which we can apply to fields of the novel and of architecture. 2018 has been a particularly fruitful year, with two major exhibitions centring on the arts under the dictatorship. The first one was organized by the Fondazione Prada in Milan and showcased more than 600 artworks covering the visual arts, architecture, literature and cinema from 1918 to 1943 . The aim of the exhibition was to show an interdisciplinary scenario, while putting the system of the arts into the context in which it had been produced. Another major exhibition on Futurist art from 1909 to 1939 'Universo futurista' was curated by Jeffrey Schnapp and Silvia Evangelista and opened at the Fondazione Cirulli on 21 April 2018. It featured over 200 artworks belonging to the Fondazione Sonia and Massimo Cirulli, and because of its chronological span it reinforced the importance of looking at Futurism not only as a pre-World War I (WWI) phenomenon, rather as a more flexible and overarching cultural, political and aesthetic project. Two further exhibitions will open shortly, one to be held contemporaneously at the Museo del Novecento in Milan and at the Mart (Museo d'Arte Contemporanea di Rovereto e Trento) in Rovereto on Margherita Sarfatti, and the other in Pordenone at the Galleria Harry Bertoia on Mario Sironi's early works. This book is the result of an ongoing dialogue, real or virtual, with all the scholars, practitioners, curators and institutions listed above and in the bibliography.

Chronologically speaking, because of the 'battle for consensus' fought by the regime, we have paid particular attention to the first half of the 1930s, when the debates around the role of the arts for the totalitarian regime as well as those around the new Italian novel and the new Italian architecture peaked in intensity and incisiveness. We have focused primarily on the journals 900, Quadrante, Occidente, Orpheus, Critica fascista, L'Italia letteraria and Il Saggiatore, because they engaged most systematically with the debate on the novel and architecture, and that on realism and the new culture. In order to offer a comprehensive picture, however, we have when necessary made references to other journals which addressed similar issues (e.g. Architettura from the point of view of leading architect Marcello Piacentini and the official architecture of Italy, and Interplanetario and La ruota dentata as expressions of the avant-gardes, before these were hegemonized by the regime). We have examined 
archival material as well as a set of novels and buildings, which can be taken as representative of the principles shared by the twin projects of renovating architecture and reconstructing the novel, as well as a series of intersecting points in the trajectory towards a modern arte di Stato. After 1936, across both fields, the international isolation faced by Italy as a consequence of the Ethiopian war caused a sea change. The novel continued to be theorized in terms of 'realism', but the architectural field became progressively less experimental and more dominated by the broad umbrella known as the monumental stile littorio. Finally, as World War II (WWII) began to loom, these debates died down and the major manifestations of State art in the field of architecture collapsed into crude monumentalism.

\section{Chapter Outline}

The book follows two main trajectories: the debate on the novel and the debate on architecture under the overarching discourse of State art. Chapter 2 engages with the notion of arte di Stato as an Italian peculiarity and thus identifies the main traits and singularities of the Fascist system of the arts, as well as of the relationship between the arts and politics under Fascism, as articulated in the various cultural and political debates on the matter which took place from the mid-1920s onwards. Chapter 3 focuses on the shape of the Italian novel in the period under scrutiny and assesses the debates concerning it. In particular, it discusses the importance of the realist novel in the construction of State art while juxtaposing the Italian novel with the phenomenon of translation, which supported the publishing industry during the whole duration of the regime. The chapter looks not only at well-known novels but also at others that have been progressively forgotten. Chapter 4 discusses the architectural debates across the two decades in order to extract the main discursive lines which defined them. From the analysis of these architectural debates, we can see how important architecture was for the shaping of the novel form. It emerges that there were many similarities with debates surrounding the novel and all focused on the morality of art, the need for construction and the social imperative, which the arts needed to acknowledge as part 
of their identity under the regime. Chapter 5 examines debates and discourses on the journals 900 and Quadrante, and we argue that they were two of the main platforms for the construction of the novel and architecture as two interlocking projects working towards the construction of a modern and interdisciplinary Fascist culture, based on the shared principles of the rationalization of style, the morality of art and the engagement with the real. Chapter 6 turns to the analysis of three journals published in Rome and Milan-Occidente, Il Saggiatore and Orpheuswhich engaged in the debate on realism as well as on the importance of morality and social engagement in the arts. These journals associated themselves with the cultural fringes of the youth culture produced by the regime and sought to offer a pragmatic solution to the debate on the new culture initiated by Critica fascista and Giuseppe Bottai and indirectly to the shape of the novel in realist terms. Chapter 7 applies the principles identified in the previous chapters to the analysis of a set of novels and buildings. These artefacts have been chosen because they epitomize the structural and conceptual intersections between architecture and the novel in more or less well-known novels and buildings. In this chapter we demonstrate how the convergence between the two artistic fields worked in practice and contributed to shaping the aesthetic, social and political meaning of the artworks in question.

\section{Notes}

1. We have not taken into consideration the last two years of the regime's history, since the political configuration of the Republic of Salò and of occupied Italy were different and the cultural debates were silenced by WWII.

2. Some key works in this field we are indebted to are: Isnenghi (1979) and Mangoni $(1974,1999)$ on the profile of Italian intellectuals, Turi (1995) on Giovanni Gentile, and on Stone (1998), while for the history of the institutions which promoted the arts, see Carli and Pontiggia (2006), De Sabbata (2007, 2012), Sagramora (2008), Salaris (2004), Salvagnini (2000) and Toffanello (2017). 
3. For a historical assessment of the relationship between the regime and the publishing industry, see Turi (1980), and on the Einaudi publishing house, Turi (1990), as well as other landmark publications, such as Finocchi and Gigli-Marchetti (1997), Tranfaglia and Vittoria (2000), and Cadioli and Vigini (2004).

4. We will return to this topic in Chap. 4, but we would like to mention some important contributions which highlighted how the regime orchestrated the staging of a particular architectural language for the display of the symbolic order it had created. See, for example, Nicoloso (2008, 2012) and, as far as rural architecture was concerned, Sabatino (2010).

5. 1932 is a turning point in the history of the regime, and the fusion of Futurist aesthetic patterns with rationalist ones on the façade of the Mostra is quite indicative of the ways in which cultural matters would be dealt in the decade to follow. On the exhibition, see Ciucci (1982), Schnapp $(2003,2004)$ and Ghirardo (1992).

6. We understand autonomy as an aesthetic practice which takes the subjective experience both as its main expressive form and as its point of refraction. On the contrary, we intend a heteronomous aesthetic practice as one that conceives of the aesthetic experience in relation to an external objective reference point.

7. We are not aware of any other publication which proposes an extended analysis of these two phenomena as intersecting ones from the point of view of two artistic practices. Often, interdisciplinary analysis is collected in edited volumes or as journal articles. Finally, we are not using the categories of modernity and Modernism as overarching ones.

8. We can certainly list Albertina Vittoria's (1983) work on Fascist periodicals as a frontrunner of this trend because of how she intersected historical and cultural discourses. Similarly, Luisa Mangoni's (1974) work on Italian intellectuals at the thresholds between the nineteenth and twentieth centuries is giving significant prominence to cultural matters vis-à-vis historical ones.

9. These works grouped together the work of architectural critics, visual art scholars, art and literary historians, historians, intellectual and cultural historians in order to offer the reader a very detailed, yet angular, view of the arts under the regime. They all acted scientifically from an interdisciplinary perspective and without privileging one perspective over the other, thereby showing the complexities, while making rather bold claims about their significance as a concerted whole. Such an approach avoided the pitfalls of a potentially reductionist ideological assessment of the arts under the dictatorship. 
Open Access This chapter is licensed under the terms of the Creative Commons Attribution 4.0 International License (http://creativecommons.org/ licenses/by/4.0/), which permits use, sharing, adaptation, distribution and reproduction in any medium or format, as long as you give appropriate credit to the original author(s) and the source, provide a link to the Creative Commons licence and indicate if changes were made.

The images or other third party material in this chapter are included in the chapter's Creative Commons licence, unless indicated otherwise in a credit line to the material. If material is not included in the chapter's Creative Commons licence and your intended use is not permitted by statutory regulation or exceeds the permitted use, you will need to obtain permission directly from the copyright holder.

(c) (i) 